\section{PET imaging of recurrent and metastatic prostate cancer with novel tracers}

\author{
Francesca V Mertan', Liza Lindenberg', Peter L Choyke' \& Baris Turkbey*,1
}

Early detection of recurrent prostate cancer ( $\mathrm{PCa}$ ) is of paramount importance to deliver prompt and accurate therapy reducing the chance of progression to metastatic disease. However, current imaging modalities such as conventional computed tomography, MRI and PET scanning do not provide sufficient sensitivity, especially at lower prostate-specific antigen values. Moreover, biological characterization of PCa has become increasingly important to provide patient-specific therapy and current imaging poorly characterizes disease aggressiveness. The current uprise of novel PET tracers in recurrent and metastatic PCa shows promising, yet variable sensitivities and specificities in detection, indicating the need for further studies. In this review, we highlight current and new PET tracers that have been developed to improve the detection of recurrent and metastatic PCa.

First draft submitted: 6 June 2015; Accepted for publication: 15 July 2016; Published online: 16 August 2016

Prostate cancer ( $\mathrm{PCa}$ ) is the most common noncutaneous malignancy in American men with 180,890 new cases and 26,120 deaths estimated in 2016 alone [1]. Recent advances in detection, monitoring and treatment of the disease include the growing use of multiparametric MRI, transrectal ultrasound/fusion MRI-guided biopsies and new focal therapies. Primary definitive therapy options for PCa remain radiation therapy (RT) and radical prostatectomy (RP), which are used with curative intent, although both methods have improved over time. Despite the high success rates in primary treatment, $15-25 \%$ of patients still experience biochemical recurrence (BCR), following primary definitive therapy with RP or RT [2-7]. The definition of BCR varies between therapy methods. For instance, following RP a rising PSA above $0.2 \mathrm{ng} / \mathrm{ml}$ defines BCR whereas following RT BCR is defined as a PSA change of $2.0 \mathrm{ng} / \mathrm{ml}$ above the nadir following RT and is known as the Phoenix criteria [7]. As rising PSA in post primary therapy patients is an indicator of PCa BCR, close monitoring of serum PSA levels following treatment is critical $[7,8]$. In the case of BCR, early detection and initiation of therapy is a key to better long-term outcomes. Early intervention is associated with a lower rate of metastatic disease. Thus, accurate and early detection of recurrence leading to earlier treatment will aid in hindering the progression of BCR to metastatic disease.

Multiple imaging modalities exist for the detection of recurrent PCa including computed tomography (CT), bone scintigraphy, MRI and PET. However, the need for more sensitive and specific imaging modalities to detect early recurrent and metastatic PCa has been prompted by evidence supporting early treatment. In addition to more sensitive and specific imaging, there has been a 'thrust' toward personalized and targeted management to discover disease phenotype and predict clinical outcomes earlier, which PET/CT has answered the call [9]. The future demands more

'Molecular Imaging Program, National Cancer Institute, NIH, Bethesda, MD, USA

*Author for correspondence: turkbeyi@mail.nih.gov

\section{KEYWORDS}

- biochemical recurrence

- PET - prostate cancer 
than a traditional approach in disease assessment and staging; it requires the exploration of tumor biology in conjunction with existing structural imaging methods to deliver personalized medicine in the case of BCR and metastatic PCa [9]. In turn, accurate localization of recurrent $\mathrm{PCa}$ at low PSA values is a major challenge as patients with BCR are best treated as early as possible [10-13]. Current imaging modalities, aside from PET/CT, are limited in detection of recurrence or metastasis for PSA values $<5 \mathrm{ng} / \mathrm{ml}$ [14]. PET imaging is unique in that it is highly sensitive and it has the ability to evaluate metabolic and molecular processes [15]. However, a major challenge among this class of agents is their low specificity and the inability to differentiate between indolent and aggressive disease $[15,16]$. Current favored tracers of PET imaging include bone scintigraphy with ${ }^{99 \mathrm{~m} T c-l a b e l e d}$ phosphonates and 2-deoxy-2- $\left[{ }^{18} \mathrm{~F}\right]$ fluoro-D-glucose, or ${ }^{18} \mathrm{~F}-\mathrm{FDG}$; however, these tracers are limited by sensitivity, specificity, metabolism and excretion methods [17-19]. Thus, the purpose of this review is to highlight the advantages and limitations of current novel PET tracers in the detection of biochemical recurrent and metastatic PCa.

\section{${ }^{11} \mathrm{C}-\&{ }^{18} \mathrm{~F}$-choline tracers}

Choline kinase is overexpressed in PCa cells, and choline is used to synthesize phosphatidylcholine, an integral component to cell membranes. Investigators have sought to radiolabel choline with ${ }^{11} \mathrm{C}$ or ${ }^{18} \mathrm{~F}$ to detect early recurrent $\mathrm{PCa}$ on PET/CT. Choline PET/CT has been shown to have high sensitivity in the detection of recurrent disease [20]. The primary mechanism of increased uptake of ${ }^{11} \mathrm{C}$ - and ${ }^{18} \mathrm{~F}$-choline tracers is the upregulated cell membrane synthesis of PCa cells and the uptake of choline in cancer cells. Though both ${ }^{11} \mathrm{C}$ - and ${ }^{18} \mathrm{~F}$-choline tracers are similar in concept and use, they differ in half-life and urinary tract excretion [21]. For instance, ${ }^{11} \mathrm{C}$-labeled choline, which has only a $20 \mathrm{~min}$ half-life, is primarily excreted via the hepatobiliary route. This means that the bladder has minimal activity reducing artifacts in the pelvis [21-23]. The short half of ${ }^{11} \mathrm{C}$ mandates that it be produced on site, requiring both a cyclotron and synthetic radiochemistry facilities. These are expensive to maintain and have come under increasing scrutiny by regulatory agencies in recent years. Alternatively, ${ }^{18} \mathrm{~F}$-choline is an agent with a half-life of $110 \mathrm{~min}$ so that it can be produced off-site in a central facility and transported to the imaging center. ${ }^{18} \mathrm{~F}$ as an isotope also has favorable positron energies, which tend to improve the quality of imaging. However, ${ }^{18} \mathrm{~F}$-choline is primarily excreted by the urinary tract and therefore has less favorable imaging characteristics in the pelvis due to bladder interference [22,23].

In a meta-analysis by Fanti et al., PET/CT with ${ }^{11} \mathrm{C}$-choline was assessed in 18 studies in patients with BCR. The pooled detection rate of ${ }^{11} \mathrm{C}$-choline PET/CT was $62 \%$, and the pooled sensitivity and specificity were both $89 \%$ in a combined population of 2686 patients [24]. A limitation of meta-analysis is that the variables in the patient population are difficult to control and thus, it is unclear whether these data are representative of the majority of patients despite the large number of patients. In a smaller, single institution study, Mitchell et al. examined ${ }^{11} \mathrm{C}$-choline PET/CT performance in 176 patients with BCR finding the sensitivity, specificity, positive predictive value and negative predictive value to be $93,76,91$ and $81 \%$, respectively on a per patient basis. The scan became very reliable for detecting recurrent disease only after the PSA was $>2.0 \mathrm{ng} / \mathrm{ml}$, which is a level associated with a poorer prognosis [25]. The ability of ${ }^{11} \mathrm{C}$-choline PET/CT to specifically highlight the location of recurrence was emphasized in a study by Garcia et al. that evaluated patients with BCR and found that it was capable of detecting metastatic lymph nodes in a high percentage. This specifically changed therapy as salvage RT was used to extend the fields to encompass the affected nodes [26]. A separate retrospective study by Incerti et al. also demonstrated that ${ }^{11} \mathrm{C}$-choline was able to detect patients who could benefit from intensitymodulated radiation therapy of recurrent lymph nodes. Results showed that the 2-year overall survival, locoregional relapse-free survival and biochemical relapse-free survival were 87, 91 and $40 \%$, respectively for 68 patients (PSA range: $0.61-27.56 \mathrm{ng} / \mathrm{ml}$ ) with a median follow-up of 20 months [27]. Another retrospective study by the same group found that ${ }^{11} \mathrm{C}$-choline PET/CT can predict survival in hormone naive PCa patients with BCR after RP. A total of 302 hormone-naive PCa patients with a median PSA of $1.02 \mathrm{ng} / \mathrm{ml}$ were included and the 15 -year PCa-specific survival probability was 42 and $95.5 \%$ in patients with positive and negative ${ }^{11} \mathrm{C}$-choline PET/CT scans, respectively [28]. Prior to this study, the same group also reported 
retrospectively that ${ }^{11} \mathrm{C}$-choline $\mathrm{PET} / \mathrm{CT}$ predicts $\mathrm{PCa}$-specific survival in patients with $\mathrm{BCR}$ during androgen deprivation therapy, since the androgen receptor (AR) has been shown to contribute to the growth of PCa. This study found that in $195 \mathrm{PCa}$ patients with RP and subsequent BCR, the median PCa-specific survival was 16.4 and 11.2 years in patients with negative and positive ${ }^{11} \mathrm{C}$-choline PET/CT scans, respectively, with a significance of $\mathrm{p}<0.001$ [29]. Given its convenience compared with ${ }^{11} \mathrm{C}$-choline, ${ }^{18} \mathrm{~F}$-choline PET/CT has been extensively tested in the BCR setting. A meta-analysis by von Eyben $e$ al. compared pooled detection rates for ${ }^{11} \mathrm{C}$ - and ${ }^{18} \mathrm{~F}$-choline and found the latter to have a statistically higher detection rate of positive findings in patients with BCR following RP (60 vs $46 \%$; $\mathrm{p}<0.0005)$ [30]. However, ${ }^{18} \mathrm{~F}$-choline is a far from perfect method even in patients at extremely high risk of recurrence. For instance, a study by Colombie et al. found that only 137 of $172(80 \%)$ of patients with a mean PSA of $10.7 \pm 35.0 \mathrm{ng} / \mathrm{ml}$, were positive on ${ }^{18} \mathrm{~F}$-choline PET/CT. Among the positive PET/CT patients, $30 \%$ had intraprostatic recurrence, $42 \%$ had pelvic lymph node recurrence, and $28 \%$ had distant metastases [31]. In populations with lower PSA levels, ${ }^{18} \mathrm{~F}$-choline performs even worse. For instance, Evangelista et al. summarized the results of a three-center study including 1031 patients (PSA range: $0.22-18.13 \mathrm{ng} / \mathrm{ml}$ ). Only $12.7 \%$ (131) of patients showed positive ${ }^{18} \mathrm{~F}$-choline uptake and of these patients, only $57 \%(\mathrm{n}=75)$ were able to have their ${ }^{18} \mathrm{~F}$-choline scans correlated to MRI and/or histopathology. Among the positive scans, $79 \%(\mathrm{n}=59)$ were true-positive ${ }^{18} \mathrm{~F}$-choline scans, while $21 \%$ were false positive. Additionally, the false-positive rate increased to $50-65 \%$ in patients with PSA $\leq 2 \mathrm{ng} / \mathrm{ml}$ [32].

Thus, despite its advantages, ${ }^{18} \mathrm{~F}$-choline has significant sensitivity and specificity issues in the evaluation of patients with BCR, problems that intensify at lower PSA values. For instance, Schiavina $e t$ al. reported that the detection rate of BCR at lower PSA levels $(<5 \mathrm{ng} / \mathrm{ml})$ was only $30-40 \%$. The dependency of performance on PSA (a surrogate for the mass of recurrent disease) was also illustrated by Zaorsky et al. who evaluated 46 published studies of ${ }^{18} \mathrm{~F}$-choline PET in the BCR setting. The pooled sensitivity and specificity for ${ }^{11} \mathrm{C}$-choline PET/CT were $38-98 \%$ and $50-100 \%$, respectively, for detecting local recurrence, lymph node and distant metastases, while ${ }^{18} \mathrm{~F}$-choline had pooled sensitivity and specificity of $47-92 \%$ and $33-99 \%$, respectively, in detecting all sites of recurrence. Thus, this study indicated a broad range of sensitivity, which varied with the amount of disease [33].

For patients suspected of harboring metastases, choline PET/CT has shown the ability to detect bone metastases. Schiavina et al. reported that the principal advantage of choline PET/CT is in its ability to detect recurrence at lower PSA levels $(<5 \mathrm{ng} / \mathrm{ml})$ with a detection rate between 30 and $40 \%$ following radical treatment and that the tracer is able to change therapeutic approaches by finding bone metastases in $15 \%$ of patients with a negative bone scan due to its better accuracy than cross-sectional imaging [34]. Similarly, Fuccio et al. showed ${ }^{11} \mathrm{C}$-choline PET/CT could detect bone metastases with a negative bone scan. Interestingly, $15 \%$ of patients previously negative on bone scan were positive on PET/CT; however, the study was limited by lack of histologic validation and variable intervals between the bone scan and PET/CT (ranging up to 4 months with a mean of 2.5 months, PSA range: $0.2-25.5 \mathrm{ng} / \mathrm{ml}$ ) [35]. Thus, choline PET/CT is more sensitive than conventional bone scan and in at-risk populations will detect approximately $15 \%$ more patients with metastatic disease.

In summary, choline PET generally performs well at high PSA values and is useful in distinguishing between locoregional recurrence versus distant PCa metastases, thus aiding in salvage and androgen-deprivation therapy treatment options [10]. However, the current body of evidence with choline-based tracers is limited due to possible study population biases and limited availability of histological validation. What emerges is that choline PET may be insufficiently sensitive to detect recurrences at low PSA values $(\sim 0.5 \mathrm{ng} / \mathrm{ml})$ to be valuable in the decision to perform salvage RT. Moreover, there are country-to-country variations in the availability of choline PET/CT. For instance, in the USA, ${ }^{11} \mathrm{C}$ choline is available at a few centers but ${ }^{18} \mathrm{~F}$-choline is not available, whereas the opposite is true in Europe. Given the success of newer PET agents, the future of this agent is uncertain.

\section{${ }^{11} \mathrm{C}$-acetate}

Fatty acid metabolism increases in PCa cells through upregulation of fatty acid synthase. Acetate is a substrate for fatty acid synthase that is 
taken up by cells and converted into acetyl-CoA, which is oxidized in the mitochondria for the production of energy, or further metabolized to be incorporated into the cellular membrane $[21,36]$. ${ }^{11} \mathrm{C}$-acetate should therefore be a biomarker of metabolic processes such as cancer. As with any ${ }^{11} \mathrm{C}$-labeled tracer, it has a relatively short half-life ( $\sim 20 \mathrm{~min}$ ) and thus requires an onsite cyclotron and radiochemistry facility. However, it has the favorable characteristic of minimal urinary tract excretion and therefore, little interference from the bladder (Figure 1). ${ }^{11} \mathrm{C}$-acetate has been well studied in the detection, recurrence, and staging of PCa [21,37-38].

In the setting of $\mathrm{BCR},{ }^{11} \mathrm{C}$-choline and ${ }^{11} \mathrm{C}$-acetate are quite similar. For instance, in a meta-analysis of 14 studies, Mohsen et al. found the pooled sensitivity for ${ }^{11} \mathrm{C}$-acetate to be $64 \%$, with a pooled specificity of $93 \%$ in distinguishing recurrent disease. The sensitivity was $20 \%$ higher in detecting recurrence in postsurgical versus post-RT patients, likely due to background uptake in patients undergoing RT. However, sensitivity was still a problem with $35 \%$ lower detection rates in patients with PSA levels $<1 \mathrm{ng} / \mathrm{ml}$ [39]. The uptake of ${ }^{11} \mathrm{C}$-acetate appears to correlate with tumor aggressiveness. Leisser et al. conducted a retrospective study on $123 \mathrm{PCa}$ patients undergoing ${ }^{11} \mathrm{C}$-acetate PET/CT and found that the standard uptake value (SUV) correlated with initial Gleason and PSA velocity. However, sensitivity was still low in patients with low PSA indicating that sensitivity was less than ideal. Median PSA value for patients with positive PET scans was significantly higher at $5.9 \mathrm{ng} / \mathrm{ml}$ (range: 0.5-99.9) than in patients with negative PET scans (median: $3.2 \mathrm{ng} / \mathrm{ml}$; range: $0.2-116$ ) [40].
Nevertheless, some studies showed slightly improved sensitivity for ${ }^{11} \mathrm{C}$-acetate compared with ${ }^{11} \mathrm{C}$-choline. For example, Dusing et al. retrospectively analyzed 120 patients with positive ${ }^{11} \mathrm{C}$-acetate PET/CT scan findings in which the PSA was at least $1.24 \mathrm{ng} / \mathrm{ml}$. The sensitivity and specificity for ${ }^{11} \mathrm{C}$-acetate were 87 and $66 \%$, respectively, and using a PSA velocity threshold of $1.32 \mathrm{ng} / \mathrm{ml} /$ year or greater produced a sensitivity and specificity of 74 and $75 \%$, respectively. These results are better than published results of ${ }^{11} \mathrm{C}$-choline at a similar distribution of PSA [41]. There are few head-to-head comparisons of ${ }^{11} \mathrm{C}$-choline and ${ }^{11} \mathrm{C}$-acetate. One study by Buchegger et al. in a group of $23 \mathrm{BCR}$ patients with low PSA values $(<5 \mathrm{ng} / \mathrm{ml})$ produced similar results on per patient and per lesion basis suggesting that both tracers perform equally well in recurrent PCa staging [42].

How does ${ }^{11} \mathrm{C}$-acetate perform in the metastatic setting? Spick et al. evaluated the detection of bone metastases using ${ }^{11} \mathrm{C}$-acetate in 90 patients. ${ }^{11} \mathrm{C}$-acetate PET detected $90 \%$ of lesions with a specificity of $96 \%$ on a per patient basis. Spick et al. also found that ${ }^{11} \mathrm{C}$-acetate detected about 7\% additional bone metastases over the bone scan [43].

Because of the absence of head-to-head comparisons of ${ }^{11} \mathrm{C}$-choline and ${ }^{11} \mathrm{C}$-acetate studies, it is difficult to ascertain which is better. In terms of detecting locoregional recurrences and metastases, there is no evidence that one agent is vastly superior to the other. All ${ }^{11} \mathrm{C}$-compounds will be limited in their distribution due to their short half-life and the differences in function appear small at this time. Importantly, only a few centers around the world are actively producing ${ }^{11} \mathrm{C}$-acetate and this fact alone will limit its use.

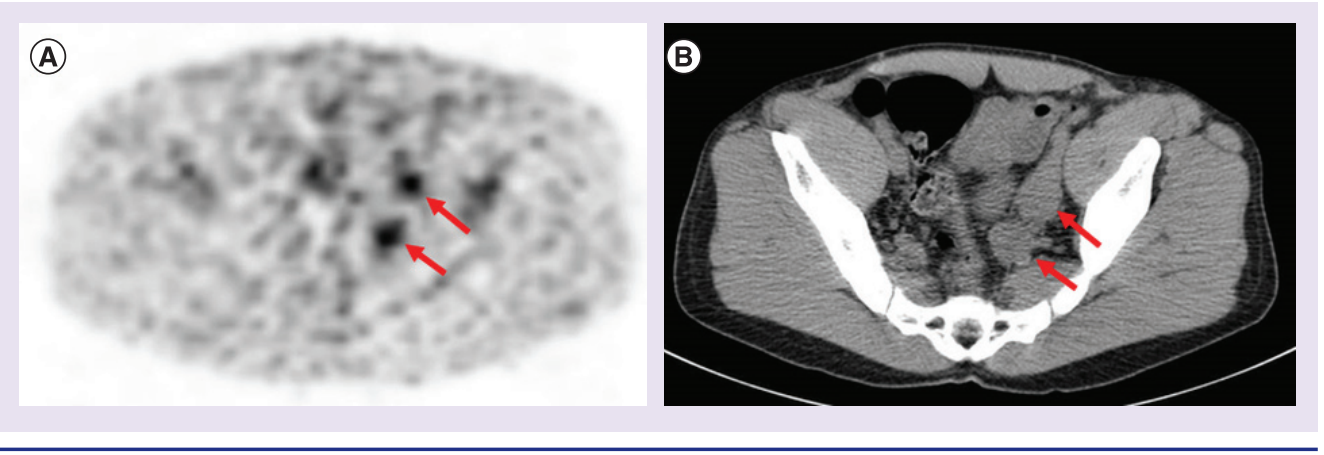

Figure 1. A 43-year-old man with a serum prostate-specific antigen of $30.4 \mathrm{ng} / \mathrm{ml}$ with Gleason 4 +5 prostate cancer. Axial ${ }^{11} \mathrm{C}$-acetate PET (A) demonstrates uptake in adenopathy in the left proximal iliac chain (arrows). Computed tomography images (B) show enlarged lymph nodes in the left proximal iliac chain consistent with nodal prostate cancer metastases (arrows). 


\section{Anti-1/2/3-18 F-flurocyclobutane-1-}

\section{carboxylic acid}

Anti-1/2/3- ${ }^{18} \mathrm{~F}$-flurocyclobutane-1-carboxylic acid $\left({ }^{18} \mathrm{~F}-\mathrm{FACBC}\right)$ is a PET tracer that has recently been approved by the US FDA for the detection of recurrent $\mathrm{PCa}$. This agent is a radiolabeled synthetic leucine analog and thus targets amino acid transport, which is upregulated in PCa $[44,45]$. This compound has slow excretion from the urinary tract reducing competing signal in the bladder [34].

In an initial prospective study by Schuster $\mathrm{et} \mathrm{al}$. of patients with a median PSA of $15 \mathrm{ng} / \mathrm{ml}$, ${ }^{18}$ F-FACBC PET/CT showed $100 \%$ sensitivity. Median PSA of participants in this small trial was $15.0 \pm 18.6 \mathrm{ng} / \mathrm{ml}$ (range: $1.9-71 \mathrm{ng} / \mathrm{ml}$ ); however, this study was limited by its small patient cohort and by the SUV $\mathrm{max}_{\text {max }}$ methodology in using a ratio of SUV $\mathrm{max}_{\text {max }}$ to muscle $S U V_{\text {mean }}$ to overcome regions of low uptake [46]. In a second study of patients with a mean PSA of $6.6 \mathrm{ng} / \mathrm{ml}$, the agent showed a sensitivity of $89 \%$ and specificity of $67 \%$ for recurrence on a per patient basis among 50 patients studied. Outside the prostatectomy bed, ${ }^{18}$ F-FACBC had $100 \%$ sensitivity $(\mathrm{n}=10)$ and specificity $(\mathrm{n}=7)$, on a per patient basis [47]. More recently Nanni et al. compared ${ }^{18} \mathrm{~F}-\mathrm{FACBC}$ to ${ }^{11} \mathrm{C}$-choline $\mathrm{PET} / \mathrm{CT}$ in 15 patients with BCR (mean PSA: $2.1 \pm 2 \mathrm{ng} / \mathrm{ml}$, range: $0.2-8.48$ ) following radical treatment of PCa. All 15 patients were post RP, while five patients received postsurgical RT and seven received postsurgical hormone therapy. This study found ${ }^{18} \mathrm{~F}-\mathrm{FACBC}$ to be superior to ${ }^{11} \mathrm{C}$-choline, almost doubling its detection rate ( 40 vs 20\%) on both per patient and per lesion bases, also finding all positive regions found with ${ }^{11} \mathrm{C}$-choline. However, this study was limited by its small patient population and there was no statistically significant difference between the two tracers $(p=0.25)$ [48]. A note should be made of the declining sensitivity as the mean PSA in the study is lower, reflecting a more activist stance on the part of referring physicians in recent years. Odewole et al. confirmed the correlation between positive ${ }^{18} \mathrm{~F}$-FACBC PET/CT scans with PSA in 53 bone scan negative patients. On a per patient basis, $78 \%$ of the ${ }^{18} \mathrm{~F}$-FACBC PET/CT scans were positive compared with $19 \%$ on CT alone for all PSA levels. However, for PSA levels $<1 \mathrm{ng} / \mathrm{ml},{ }^{18} \mathrm{~F}-\mathrm{FACBC}$ was positive in only $37.5 \%$, whereas this rose to $78 \%$ for PSA levels between 1 and $2 \mathrm{ng} / \mathrm{ml}$. Additionally, Odewole et al. found that ${ }^{18} \mathrm{~F}-\mathrm{FACBC}$ was better in demarcating prostatic and extraprostatic recurrence. However, the CTs were performed for an average of 46 days before the ${ }^{18} \mathrm{~F}$-FACBC scans and 23 patients did not have intravenous contrast agent added during CT. Though a separate analysis with CT contrast did not change the outcome of the study, these two limitations are important to consider [49]. Assuming equal populations, these results make ${ }^{18} \mathrm{~F}-\mathrm{FACBC}$ PET/CT more sensitive than choline and acetate imaging for lower PSA settings but leave the possibility of other agents with better sensitivities at lower PSA values wide open.

Recently, ${ }^{18}$ F-FACBC PET/CT has been approved for use in the USA. The trials that form the basis of this approval have not yet been published but clearly were favorable with regard to other existing PET probes. The approval of ${ }^{11} \mathrm{C}$-choline in 2012 was limited to single institution use so that the current approval ${ }^{18} \mathrm{~F}-\mathrm{FACBC}$ is the first, major approval of a PET probe for PCa recurrence that could have broad implications for patient access.

\section{6beta- ${ }^{18} \mathrm{~F}$-fluoro-5alpha- dihydrotestosterone}

The AR plays a central role in growth of PCa. The normal AR is activated by dihydrotestosterone (DHT, a derivative of testosterone), in the cytoplasm, which becomes a promoter for a host of growth-directed downstream client genes, including PSA [21,50]. With time the AR can mutate so that DHT no longer is necessary to promote downstream genes and the patient becomes 'androgen independent'. 16beta- ${ }^{18} \mathrm{~F}$-fluoro-5alpha-dihydrotestosterone $\left({ }^{18} \mathrm{~F}-\mathrm{FDHT}\right) \mathrm{PET}$ is a tracer used to delineate expression of AR in metastatic PCa lesions. The ${ }^{18} \mathrm{~F}-\mathrm{FDHT}$ PET tracer binds to the AR as it is the natural ligand. This agent has mostly been used in specific drug development. For instance, in the development of the drug enzalutamide, ${ }^{18} \mathrm{~F}-\mathrm{FDHT}$ was used to show that the drug blocked the DHT-binding site on the AR, thus showing a pharmacodynamic effect. It has not been used widely outside of this research setting, and has been limited.

In a prospective study, Larson et al. performed a feasibility study of ${ }^{18} \mathrm{~F}-\mathrm{FDHT}$ versus ${ }^{18} \mathrm{~F}-\mathrm{FDG}$ in a small group of PCa patients with advanced metastases and very high PSA values (median PSA: 69 ng/ml; range: 6.3-2637). On a per lesion basis, this study found ${ }^{18} \mathrm{~F}-\mathrm{FDHT}$ was able to localize $78 \%$ of lesions compared 
with ${ }^{18} \mathrm{~F}-\mathrm{FDG}$ finding $97 \%$ of the lesions [51]. Dehdashti et al. performed another prospective feasibility study on ${ }^{18} \mathrm{~F}$-FDHT PET/CT in a group of 19 patients with advanced PCa. Mean PSA was $86.9 \mathrm{ng} / \mathrm{ml}$ for all patients, and the mean PSA of patients with positive ${ }^{18} \mathrm{~F}-\mathrm{FDHT}$ PET was significantly higher than in patients with negative ${ }^{18} \mathrm{~F}$-FDHT PET scans $(\mathrm{p}=0.006)$. Results indicated that ${ }^{18} \mathrm{~F}-\mathrm{FDHT}$ showed an overall sensitivity of $63 \%$ and a lesion detection rate of $86 \%$ [52]. Beattie et al. confirmed that ${ }^{18} \mathrm{~F}$-FDHT uptake was related to AR levels in the cancers. This study was conducted in 13 prospectively selected patients with advanced disease (median PSA: $94.65 \mathrm{ng} / \mathrm{ml}$; range: 0.49-885.05) [53]. Vargas et al. also compared ${ }^{18} \mathrm{~F}-\mathrm{FDHT}$ PET/CT and ${ }^{18} \mathrm{~F}-\mathrm{FDG}$ PET/CT tracers with two readers in 38 castration-resistant $\mathrm{PCa}$ patients, retrospectively, with bone metastases and mean PSA of $43.5 \mathrm{ng} / \mathrm{ml}$ (range: 0-389.3) at the time of study. Results showed that patients with higher ${ }^{18} \mathrm{~F}-\mathrm{FDHT}$ uptake had slightly shorter survival (reader 1: HR: $1.078 ; \mathrm{p}=0.02$; reader 2 : HR: 1.092 ; $\mathrm{p}=0.02)$, but ${ }^{18} \mathrm{~F}-\mathrm{FDG}$ uptake did not correlate with shorter survival (reader $1: p=0.65$; reader $2: p=0.38)$. Thirty-three patients were followed until death and five patients were followed for an average of 37.5 months until death (range: 6.6-59.1 months) [54]. Thus, ${ }^{18} \mathrm{~F}-\mathrm{FDHT}$ use has been confined to patients with advanced PCa and has been useful in drug development, but there is no compelling evidence that it could be useful on a broader scale as most agents are positive in this advanced setting from a diagnostic perspective. Additionally, studies on ${ }^{18} \mathrm{~F}$-FDHT are limited with small patient populations. Nevertheless, this agent remains a potentially useful part of the portfolio of PCa imaging agents as it is the only one that informs on the status of the AR which plays such a central role in PCa $[21,50,52,55]$.

\section{${ }^{18} \mathrm{~F}-\mathrm{NaF}$}

Bone metastases in PCa tend to be osteoblastic. The cancer cells induce bone to be laid down and thus agents that are taken up in the bone-forming process will be positive. This is the theory behind conventional bone scanning agents that do not utilize positron emitters. Sodium fluoride $\left({ }^{18} \mathrm{~F}\right.$ $\mathrm{NaF}$ ) is a relatively older tracer used for imaging skeletal disease for bone metastases in several cancer types including PCa. Compared with the traditional bone scan, ${ }^{18} \mathrm{~F}-\mathrm{NaF}$ PET/CT has shown improved sensitivity, but lacks specificity as it also can detect nontumor pathologies such as degenerative osteopathy, healing fractures, bone dysplasia or any other process in which bone is laid down [21]. Initially approved by the FDA in 1972 , this tracer is an inorganic chemical compound that dissociates into $\mathrm{Na}+$ and $\mathrm{F}$ - ions. The F- ions are quickly taken up in the active bone by chemisorption and label areas of increased bone growth $[56,57] .{ }^{18} \mathrm{~F}-\mathrm{NaF}$ is advantageous due to its rapid bone-specific uptake, lack of blood pool and good axial skeletal visualization due to its integration into the hydroxyapatite-collagen matrix (Figure 2) $[10,37]$. Thus, ${ }^{18} \mathrm{~F}-\mathrm{NaF}$ has no role outside of detecting bone metastases.

A prospective evaluation of ${ }^{18} \mathrm{~F}-\mathrm{NaF}$ was performed by Jadvar $e t$ al. to compare this tracer with FDG PET/CT in the detection of occult metastatic disease using a combination of conventional imaging and clinical follow-up as the reference standard. A total of 37 men at risk for metastases but not yet diagnosed were studied and showed a $16.2 \%$ rate of positivity for ${ }^{18} \mathrm{~F}-\mathrm{NaF}$ PET/CT but only $8.1 \%$ for FDG PET/CT. This study also found a positive trend of ${ }^{18} \mathrm{~F}-\mathrm{NaF}$ positivity with increasing PSA in men post RP. Median PSA for patients with a positive ${ }^{18} \mathrm{~F}-\mathrm{NaF}$ PET/CT was $4.1 \mathrm{ng} / \mathrm{ml}$ (range: 1.9-5.8) whereas it was $2.9 \mathrm{ng} / \mathrm{ml}$ (range: $0.5-40.2 \mathrm{ng} / \mathrm{ml}$ ) for patients with negative scans, a difference that proved not to be significant $(\mathrm{p}=0.31)$ [58]. In a literature review by Wondergem et al. of 11 articles pertaining to ${ }^{18} \mathrm{~F}-\mathrm{NaF}$ PET/CT with varying PSA levels, ${ }^{18} \mathrm{~F}$ $\mathrm{NaF}$ in the detection of PCa bone metastases produced pooled sensitivities of 89 and $87 \%$, and specificities of 91 and $80 \%$ on a per lesion and per patient basis, respectively [59]. A recent literature review by Azad et al. concluded that ${ }^{18} \mathrm{~F}-\mathrm{NaF}$ and ${ }^{11} \mathrm{C}$ and ${ }^{18} \mathrm{~F}$-choline PET/CT have equivalent sensitivities in finding PCa bone metastases although specificity is higher for the choline-based agents [60]. The role of ${ }^{18} \mathrm{~F}-\mathrm{NaF}$ in monitoring patients has been unclear. A recent prospective study by Apolo et al. analyzed 60 advanced $\mathrm{PCa}$ patients, 30 of whom had no known bone metastases at enrollment (median PSA: $10.97 \mathrm{ng} / \mathrm{ml}$ [range: 0.01-190]), and 30 of whom had known metastases (median PSA: $9.93 \mathrm{ng} / \mathrm{ml}$ [range: 0.1-593]). As expected ${ }^{18} \mathrm{~F}$ $\mathrm{NaF}$ PET/CT detected more bone metastases than traditional bone scan on a per patient basis and that there was a correlation between overall survival and the baseline number of malignant 
lesions on ${ }^{18} \mathrm{~F}-\mathrm{NaF}$ PET/CT and changes in SUV on subsequent ${ }^{18} \mathrm{~F}-\mathrm{NaF}$ PET/CT scans [37].

The advantages of ${ }^{18} \mathrm{~F}-\mathrm{NaF}$ PET/CT are that it is clearly more sensitive than bone scan for the detection of early bone metastases. It can be performed more rapidly after injection (1 h) than bone scan $(3-4 \mathrm{~h})$. Because it is combined with CT, obvious degenerative disease can be seen at one setting without acquiring additional studies. However, once the diagnosis of bone metastasis is established there does not seem to be a compelling advantage to its use. In fact, some investigators dislike its higher sensitivity as it makes the discussion with the patient more complicated. Although this agent was approved for use by the FDA, to date, it has not been approved for reimbursement due to the lack of compelling clinical data. Hopefully, this agent will be made available for patients at risk for metastatic disease in whom the conventional bone scan is equivocal or negative. However, it is also possible that this agent will be supplanted by other agents discussed here.

\section{Prostate-specific membrane antigen-targeted tracers}

Prostate-specific membrane antigen (PSMA) is a type II transmembrane glycoprotein expressed prominently on the surface of PCa cells. PSMA levels correlate well with androgen deprivation, disease progression and metastasis. It is associated with more aggressive forms of the disease [61]. Although its function is obscure, and cancer cells can grow without it being present, it presents an attractive target for imaging and therapy. Therefore, a number of PET agents have been developed to bind to PSMA. PSMA targeting tracers for PET/CT include both lowmolecular weight radiopharmaceutical-based imaging tracers and macromolecular antibodies, although we will not focus on the latter here. As a group, PSMA agents have shown high affinity even at low PSA values and have quickly become the 'lead horse' in the race for an effective BCR detection agent $[62,63]$.

Even though the field is relatively young, multiple generations of PSMA-targeted small molecules have been developed and tested. The most extensively studied tracer and most widely used is the ${ }^{68} \mathrm{Ga}$-labeled PSMA HBED-CC $\left({ }^{68} \mathrm{Ga}-\mathrm{PSMA}\right)$ PET tracer that was developed in Germany. ${ }^{68} \mathrm{Ga}$-PSMA has been shown to have better detection rates than ${ }^{18} \mathrm{~F}$-choline tracers in the case of recurrent and primary PCa [38,64-68].

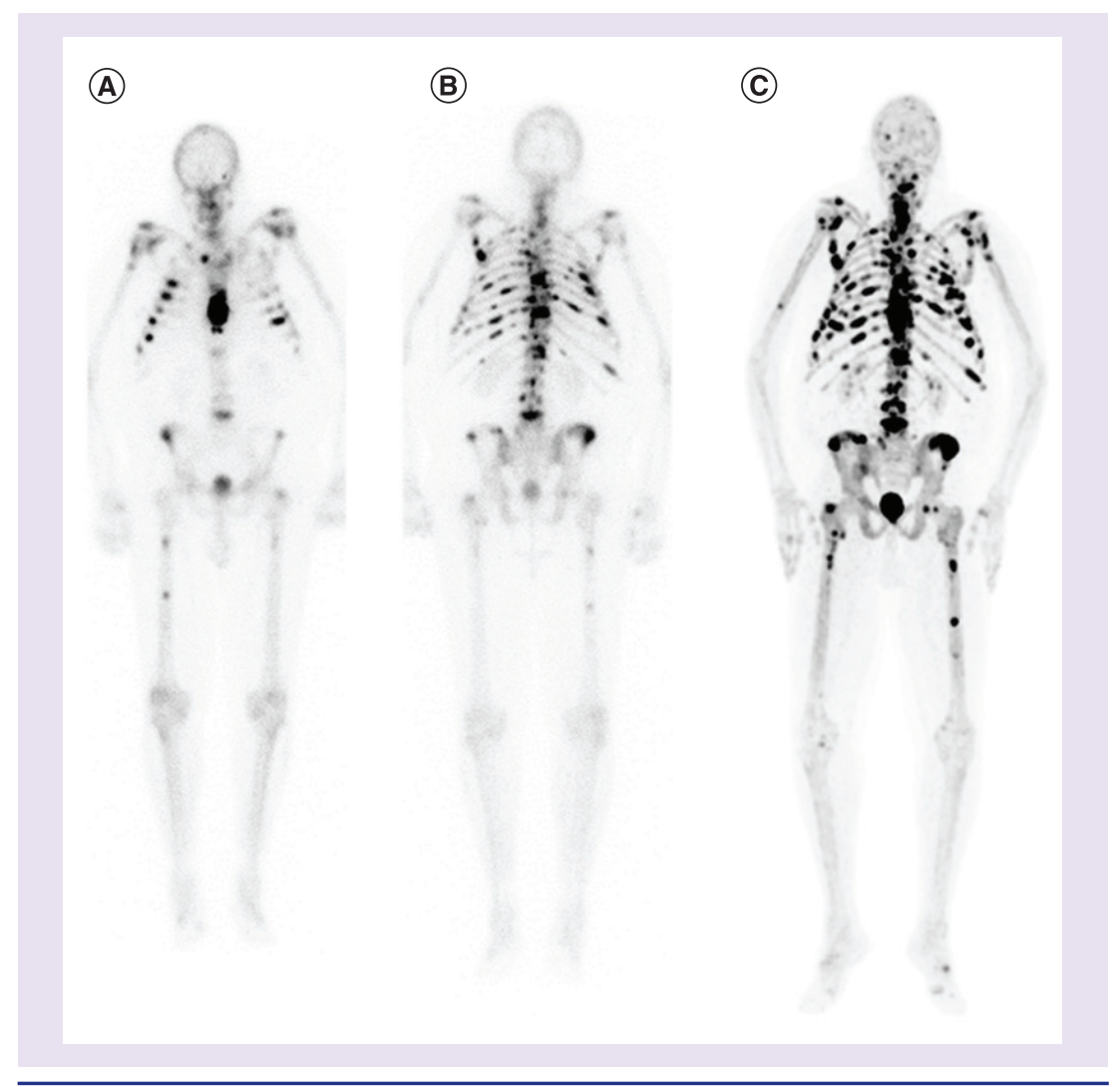

Figure 2. A 68-year-old male with a serum prostate-specific antigen of $6.8 \mathrm{ng} / \mathrm{ml}$ and Gleason $4+5$ prostate cancer diagnosis. The (A) anterior and (B) posterior projections of technetium bone scans show metastatic lesions in the axial skeleton, ribs and bilateral femur. Coronal ${ }^{18} \mathrm{~F}-\mathrm{NaF}$ PET image (C) not only confirms presence of these bony lesions, but also reveals additional widespread bony lesions that appear to be more helpful in estimation of the bony metastases burden compared with technetium bone scan.

A recent systematic review and meta-analysis by Perera et al. examined the sensitivity, specificity and predictors of ${ }^{68} \mathrm{Ga}-\mathrm{PSMA}$ PET/CT in advanced PCa since current data are somewhat limited due to this tracer's novelty. In this comprehensive review of 16 articles with a total of 1309 patients, the authors found pre-PET PSA to predict positive ${ }^{68} \mathrm{Ga}-\mathrm{PSMA}$ PET/CT since the percentage of positive ${ }^{68} \mathrm{Ga}-\mathrm{PSMA}$ PET/CT scans increased with increasing PSA. This analysis demonstrates the ability of ${ }^{68} \mathrm{Ga}$-PSMA PET/CT to detect recurrence even at low PSA values with a pooled positive detection rate of $42 \%$ in detecting disease recurrence. Additionally, four studies met the inclusion criteria for reporting histology-proven disease and the summary per patient sensitivity and specificity were both $86 \%$. On a per lesion basis, the summary sensitivity and specificity were 80 and $97 \%$, respectively, from the four included studies [69]. 
Another study by Afshar-Oromieh et al. in 2015 retrospectively evaluated 319 patients with ${ }^{68} \mathrm{Ga}$-PSMA PET/CT in primary, recurrent and metastatic PCa. The median PSA for the 264 patients with tracer uptake was $6.02 \mathrm{ng} / \mathrm{ml}$ (range: $0.01-41,395)$ and was $1.14 \mathrm{ng} / \mathrm{ml}$ for 55 patients with no pathological findings (range: 0.03-15.8). While this statistic is initially disappointing, overall $83 \%$ of patients showed ${ }^{68} \mathrm{Ga}$-PSMA uptake, and the tumor detection was correlated with PSA level. The sensitivity and specificity on a per lesion basis were 76.6 and $100 \%$, respectively. However, there were 30 false negatives among 416 lesions and only 42 patients underwent histological verification [70]. In the case of BCR following RP, a study by Eiber $e t$ al. retrospectively evaluated 248 patients with BCR following RP (median PSA: $1.99 \mathrm{ng} / \mathrm{ml}$ ) with ${ }^{68} \mathrm{Ga}$-PSMA ligand PET/CT. The patient-based detection rates for positive pathological findings were $97,93,73$ and $58 \%$ for PSAs $\geq 2,1$ to $<2,0.5$ to $<1$ and 0.2 to $<0.5 \mathrm{ng} / \mathrm{ml}$, respectively. The detection rate improved with higher PSA velocities as well. The overall detection rate was $90 \%$. These results are superior to the other agents previously discussed with impressive results even at low PSA levels. This study found ${ }^{68} \mathrm{Ga}$-PSMA PET/CT to have higher detection rates with smaller PSA values compared with other PET tracers, ultrasonography, CT and MRI; however, a major limitation of this study was that only $37.1 \%$ of patients $(92 / 248)$ had a comprehensive reference standard (histopathology, decrease in PSA after target RT or confirmed by follow-up imaging modalities) in addition to its relatively high false-negative rate [62]. Thus, these results await confirmation in more carefully controlled clinical studies.

Similar results with similar methodologies have been published by other investigators. For instance, van Leeuwen $e t$ al. prospectively examined 70 patients with BCR with ${ }^{68} \mathrm{Ga}$-PSMA PET/CT following RP with two readers. Again, the rate of positivity depended on PSA values with an $8 \%$ sensitivity for PSA levels between 0.05 and $0.09 \mathrm{ng} / \mathrm{ml}, 23 \%$ for PSA level between 0.1 and $0.19 \mathrm{ng} / \mathrm{ml}, 58 \%$ for PSA level between 0.2 and $0.3 \mathrm{ng} / \mathrm{ml}, 36 \%$ for PSA levels between 0.3 and $0.5 \mathrm{ng} / \mathrm{ml}$ and $57 \%$ for PSA level between 0.5 and $0.99 \mathrm{ng} / \mathrm{ml}$. These results confirm the first results and extended observations to include utility in restaging of $\mathrm{PCa}$ patients with rising PSA levels for metastatic disease; however, this study was also limited by a lack of histologic confirmation [71].
Few comparative studies of PSMA agents have been performed. In one, ${ }^{68} \mathrm{Ga}$-PSMA was compared with ${ }^{18} \mathrm{~F}$-choline. ${ }^{68} \mathrm{Ga}$-PSMA had higher detection rates in BCR [72-74]. However, results from these studies include small patient populations with limited histological follow-up. Future directions of ${ }^{68} \mathrm{Ga}$-PSMA include utilizing it on PET/MRI scanners rather than using PET/CT [75,76].

In addition to ${ }^{68} \mathrm{Ga}-\mathrm{PSMA}$, two alternative PSMA-targeting tracers $\mathrm{N}-[\mathrm{N}-[(\mathrm{S})-1,3-$ dicarboxypropyl] carbamoyl] $-4-{ }^{18} \mathrm{~F}$-fluorobenzylL-cystein $\left({ }^{18} \mathrm{~F}\right.$-DCFBC) and ${ }^{18} \mathrm{~F}$-DCFPyL have been recently tested. These fluorine-based compounds have theoretical advantages. ${ }^{18} \mathrm{~F}$ is a superior positron emitter compared with ${ }^{68} \mathrm{Ga}$ based on energy spectra. Moreover, it has a longer halflife enabling centralized distribution whereas ${ }^{68} \mathrm{Ga}$ must be produced on site via a 'generator' which requires considerable upfront expenditure and a radiopharmacy. A study by Rowe et al. determined that ${ }^{18} \mathrm{~F}$-DCFBC PET/CT was able to detect more lesions than conventional imaging methods in 17 prospectively enrolled patients (PSA range: $3.5-564.5 \mathrm{ng} / \mathrm{ml}$ ) on a per lesion basis. Additionally, this study found ${ }^{18} \mathrm{~F}-\mathrm{DCFBC}$ tended to have higher sensitivity (0.92) than conventional imaging methods (0.71) on follow-up. Figures 3 \& 4 demonstrate two examples of suspected local recurrence and metastasis, respectively. However, ${ }^{18} \mathrm{~F}-\mathrm{DCFBC}$ PET/CT was found to have significant blood-pool activity, which could potentially obscure evaluation of nodal disease [77]. A second-generation agent, ${ }^{18} \mathrm{~F}-\mathrm{DCFPyL}$ has just recently been studied in BCR and results in higher tumor to blood uptake ratios due to its higher affinity and lower background signal compared with ${ }^{18} \mathrm{~F}$-DCFBC PET/CT [78,79]. It also compares favorably to ${ }^{68} \mathrm{Ga}$-PSMA. Dietlein et al. reported 14 patients with BCR (PSA range: $0.17-50 \mathrm{ng} / \mathrm{ml}$ ) who underwent both ${ }^{18} \mathrm{~F}-\mathrm{DCFPyL}$ PET/CT and ${ }^{68} \mathrm{Ga}$-PSMA PET/CT. ${ }^{18} \mathrm{~F}-\mathrm{DCFPyL}$ was able to detect all lesions whereas ${ }^{68} \mathrm{Ga}$-PSMA PET/CT missed lesions in three patients. Higher mean SUVs were observed in ${ }^{18} \mathrm{~F}$-DCFPyL than in ${ }^{68} \mathrm{Ga}$-PSMA scans indicating that this tracer is encouraging as an alternative to ${ }^{68} \mathrm{Ga}-\mathrm{PSMA}$ PET/CT in the detection of recurrent PCa [80].

Overall, the PSMA agents as a class have a higher detection rate for BCR and metastatic PCa compared with other PET imaging tracers [63]. Though, PSMA-based PET imaging is still considered experimental, the future of this tracer is promising in the detection of biochemical 

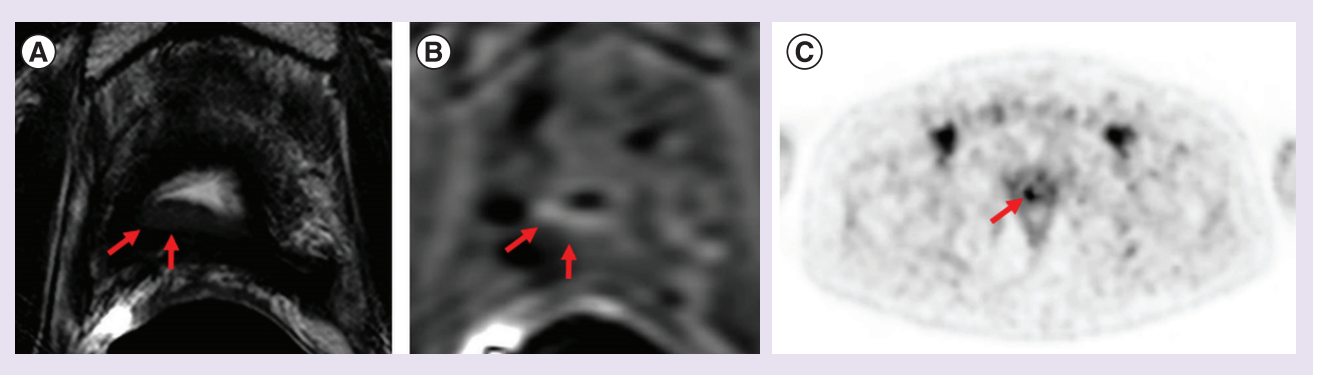

Figure 3. A 63-year-old male with a serum prostate-specific antigen of $0.61 \mathrm{ng} / \mathrm{ml}$ and primary biopsy confirmed Gleason $3+4$ prostate cancer. The patient is tatus post-radical prostatectomy. Axial T2-weighted MRI (A) shows a lesion at the right side of the anastomosis (arrows), which also demonstrates early enhancement on dynamic contrast-enhanced MRI (B) (arrows). ${ }^{18}$ F-DCFBC PET (C) shows specific uptake within this lesion, which suggests residual/recurrent prostate cancer (arrow).

recurrent and metastatic $\mathrm{PCa}$ and this, in turn, could have implications for targeted radioguided surgery and other focal therapies. More prospectively, trials with histologic confirmation are necessary to further confirm the use of this tracer [12]. At present, there are several companies pursuing approval for various agents around the world and it should be interesting to see how the outlook changes for prostate-targeted PET agents in the near future.

\section{Bombesin analog agents}

New emerging tracers in the detection of early PCa BCR include radiolabeled bombesin analogs. Bombesin is a linear tetradecapeptide and antagonist of the gastrin-releasing peptide receptor (GRP), which interacts to enhance growth of PCa cells. It has been shown that PCa strongly expresses GRP. The radiolabeled bombesin analogs allow the expression of GRP receptors, thereby detecting the location of recurrence.

Few studies have explored the efficacy of this tracer, but most recently, a study by Sah et al. performed the first clinical evaluation of ${ }^{18} \mathrm{~F}$-bombesin PET/CT in five men with PSA recurrent $\mathrm{PCa}$ and compared results to that of ${ }^{18} \mathrm{~F}$-choline PET/CT. In two out of five patients $(40 \%),{ }^{18} \mathrm{~F}$-bombesin was positive, but was positive in all patients on ${ }^{18} \mathrm{~F}$-choline [81]. In another first clinical evaluation of a bombesin analog, Kahkonen et al. studied the effect of ${ }^{68} \mathrm{Ga}$-bombesin PET/CT in the detection of metastatic $\mathrm{PCa}$ in three $\mathrm{BCR}$ patients following RP or hormone therapy (PSA levels: 0.36, 4.7 and $282 \mathrm{ng} / \mathrm{ml}$ ). This study found the tracer to exhibit fast excretion through the kidneys and $25 \%$ of the injected dose still observed in the urinary tract $30 \mathrm{~min}$ postinjection. Additionally, the tracer was positive in the two hormone-naive patients with BCR (67\%). ${ }^{68} \mathrm{Ga}$-bombesin BCR results were compared with ${ }^{11} \mathrm{C}$-acetate $\mathrm{PET} / \mathrm{CT}$ $(\mathrm{n}=2)$ and ${ }^{18} \mathrm{~F}$-choline PET/CT $(\mathrm{n}=1)$, finding the two patients with ${ }^{11} \mathrm{C}$-aceta PET/CT to be in accordance, but ${ }^{68} \mathrm{Ga}$-bombesin was not positive in the evidently positive ${ }^{18} \mathrm{~F}$-choline PET/CT [82]. Though promising, the true potential of this tracer remains unknown as current studies remain with very small patient populations and also due to the relative new nature of this tracer. Future studies with larger patient cohorts are necessary to confirm the significance of bombesin-labeled tracers in recurrent PCa.

A list of all tracers included in this manuscript along with their half-life, cyclotron requirements, action mechanism, excretion characteristics, pooled sensitivities, pooled specificities, advantages and disadvantages for the detection of recurrent and metastatic PCa at all PSA levels is provided in Table 1.
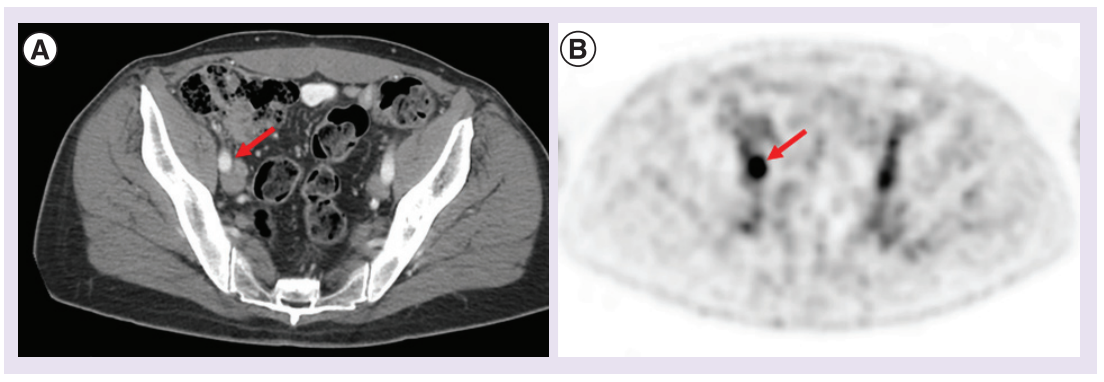

Figure 4. A 63-year-old man with a serum prostate-specific antigen of $2.58 \mathrm{ng} / \mathrm{ml}$, who underwent radical prostatectomy for Gleason $5+4$ prostate cancer. Axial contrast-enhanced computed tomography (A) shows a subcentimeter lymph node in the right iliac chain (arrow). ${ }^{18} \mathrm{~F}-\mathrm{DCFBC}$ PET image (B) demonstrates specific radiotracer uptake within this right iliac chain lymph node suggestive of prostate cancer metastases (arrow). 
REVIEW Mertan, Lindenberg, Choyke \& Turkbey

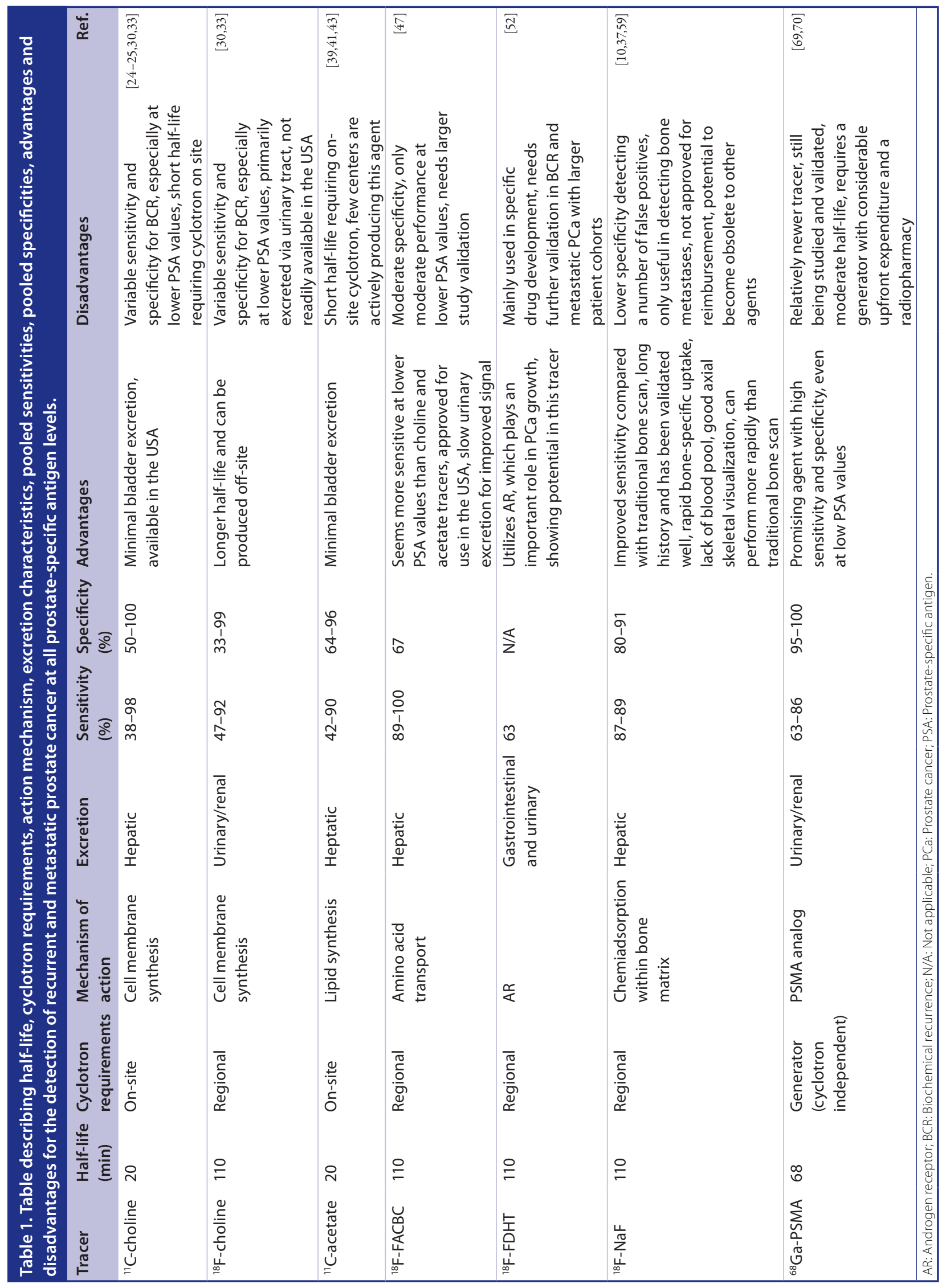




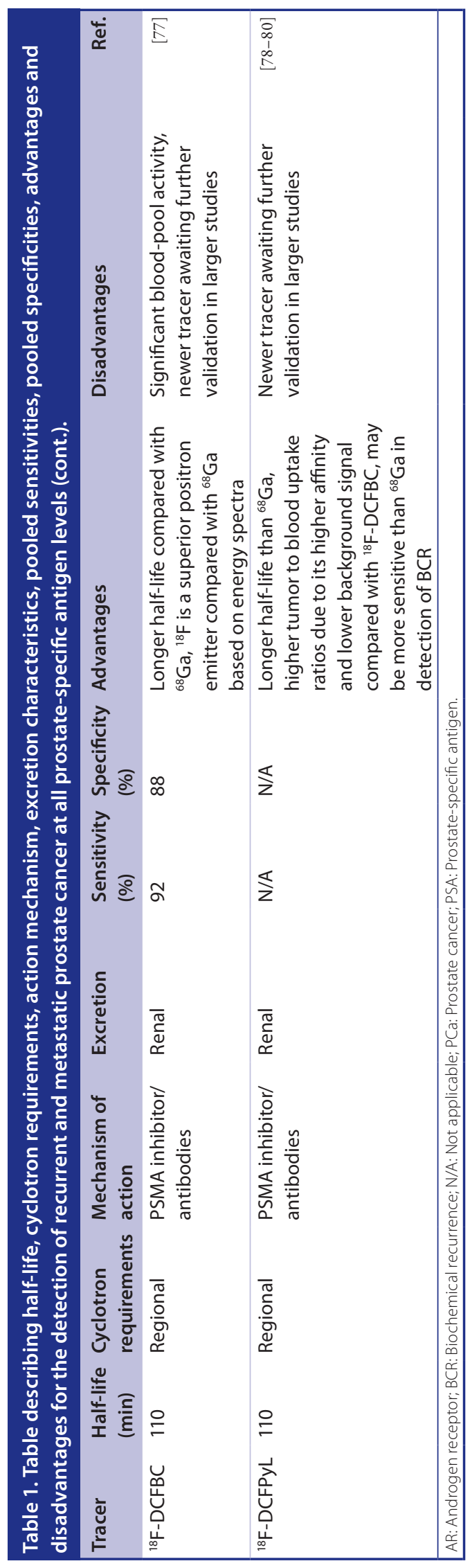

\section{Conclusion}

The ideal imaging agent for PCa would detect only clinically significant disease at first diagnosis, at recurrence and at the first signs of metastasis. It would have few false positives and be convenient to use. It would be capable of detecting recurrent disease at PSA values $<0.5 \mathrm{ng} / \mathrm{ml}$. Decisions regarding its use would be based on studies that were well controlled with histologic correlation. Armed with such an agent, the treatment of PCa could be very different. Focal therapies for primary disease and recurrent disease could be developed. Even focal therapies for early metastatic disease could be developed. Patients might not have to undergo long courses of androgen-deprivation therapy. Thus, early detection of recurrent and metastatic $\mathrm{PCa}$ is imperative in improving the diagnosis and management of $\mathrm{PCa}$.

Clearly, none of the PET imaging agents discussed here meet all the criteria for the ideal agent. The current portfolio of agents ${ }^{18} \mathrm{~F} /{ }^{11} \mathrm{C}$ choline, ${ }^{11} \mathrm{C}$-acetate, ${ }^{18} \mathrm{~F}$-FACBC, ${ }^{18} \mathrm{~F}$-FDHT, ${ }^{18} \mathrm{~F}-\mathrm{NaF}$ and PSMA-targeted tracers have flaws. Yet, it is important to develop these agents further and establish a single agent that could serve as the standard bearer. Whichever of these PET tracers prove most effective, it is clear that they will change our understanding of the disease and facilitate the development of new therapies that maximize survival and minimize the side effects of treatment.

\section{Future perspective}

In the case of BCR, early detection and initiation of therapy is a key to better long-term outcomes. Early intervention is associated with a lower rate of metastatic disease. Thus, accurate and early detection of recurrence leading to earlier treatment will aid in hindering the progression of BCR to metastatic disease. Currently, conventional imaging techniques such as CT, bone scan and MRI are commonly used; however, their utility in detecting early BCR is quite limited. PET imaging offers specific imaging in several malignancies, but in the case of PCa BCR, the use of PET imaging is limited. Several tracers exist such as radiolabeled choline, acetate, ${ }^{18} \mathrm{~F}-\mathrm{FACBC}$, ${ }^{18} \mathrm{~F}-\mathrm{FDHT}$, PSMA-targeting agents and several studies have investigated these tracers. Yet, these studies are limited due to potential patient selection bias, limited study designs and gold standard validation. Moreover, these 
tracers suffer in sensitivity at lower PSA levels (e.g., PSA $<2-5 \mathrm{ng} / \mathrm{ml}$ ), with the exception of PSMA-targeting tracers that offer relatively higher sensitivity and specificity compared with the others. Further studies with prospective methods and focus on lower PSA values will determine the ideal radiotracer for the detection of $\mathrm{PCa}$ BCR in the future.
Financial \& competing interests disclosure The authors are NIH employees. The authors have no other relevant affiliations or financial involvement with any organization or entity with a financial interest in or financial conflict with the subject matter or materials discussed in the manuscript apart from those disclosed.

No writing assistance was utilized in the production of this manuscript.

\section{EXECUTIVE SUMMARY}

- Early detection and initiation of therapy is a key to better long-term outcomes in biochemical recurrence.

- Accurate localization of recurrent prostate cancer at low PSA values is a major challenge as patients with biochemical recurrence are best treated as early as possible.

- Current imaging modalities, aside from PET/computed tomography, are limited in detection of recurrence or metastasis for PSA values $<5 \mathrm{ng} / \mathrm{ml}$.

- ${ }^{11} \mathrm{C} /{ }^{18} \mathrm{~F}$-choline, ${ }^{11} \mathrm{C}$-acetate, anti-1/2/3-18 $\mathrm{F}$-flurocyclobutane-1-carboxylic acid have reasonable sensitivity at higher PSA levels in the setting of PSA, but these agents suffer in sensitivity at lower PSA levels $(<1 \mathrm{ng} / \mathrm{ml})$.

- 16 beta $-{ }^{18} \mathrm{~F}$-fluoro-5alpha-dihydrotestosterone targets androgen receptors, and few studies report its utility on androgen receptor status, which may assist to depict castrate-resistant prostate cancer lesions.

- ${ }^{18} \mathrm{~F}-\mathrm{NaF}$ targets bone-forming processes and detects tumor-associated osteoblastic lesions as well as healing fractures, bone dysplasia, etc.

- Prostate-specific membrane antigen-targeting tracers are current highly studied agents both in the USA and Europe. Recent studies report promising sensitivity and specificity even at lower PSA values; however, more tissue validation-based data are required to better understand this tracer.

- PET imaging with novel tracers will change our understanding of the disease and facilitate the development of new therapies that maximize survival and minimize the side effects of treatment.

\section{References}

Papers of special note have been highlighted as:

- of interest; $\bullet$ of considerable interest

1 Siegel RL, Miller KD, Jemal A. Cancer statistics, 2016. CA Cancer J. Clin. 66(1), 7-30 (2016).

2 Shikanov S, Kocherginsky M, Shalhav AL, Eggener SE. Cause-specific mortality following radical prostatectomy. Prostate Cancer Prostatic Dis. 15(1), 106-110 (2012).

3 Moul JW. Prostate specific antigen only progression of prostate cancer. J. Urol. 163(6), $1632-1642(2000)$.

4 Laufer M, Pound CR, Carducci MA, Eisenberger MA. Management of patients with rising prostate-specific antigen after radical prostatectomy. Urology 55(3), 309-315 (2000).

5 Zumsteg ZS, Spratt DE, Romesser PB et al. Anatomical patterns of recurrence following biochemical relapse in the dose escalation era for prostate patients undergoing external beam radiotherapy. J. Urol. 194(6), 1624-1630 (2015).
6 Zumsteg ZS, Spratt DE, Romesser PB et al. The natural history and predictors of outcome following biochemical relapse in the dose escalation era for prostate cancer patients undergoing definitive external beam radiotherapy. Eur. Urol. 67(6), 1009-1016 (2015).

7 Mertan FG Md, Borofsky S, Kabakus I et al. Multiparametric magnetic resonance imaging of recurrent prostate cancer. Top. Magn. Reson. Imaging 25(3), 139-147 (2016).

8 Levent Kabasakal ED. PSMA PET/CT imaging therapy. J. Imaging Interv. Radiol. 1(2), 16 (2015).

9 Basu S, Alavi A. PET-based personalized management in clinical oncology: an unavoidable path for the foreseeable future. PET Clin. 11(3), 203-207 (2016).

10 Leiblich A, Stevens D, Sooriakumaran P. The utility of molecular imaging in prostate cancer. Curr. Urol. Rep. 17(3), 26 (2016).

11 Evangelista L, Zattoni F, Rossi E, Karnes RJ, Lowe V. Early detection of prostate cancer relapse by biochemistry and diagnostic imaging. Q. J. Nucl. Med. Mol. Imaging 59(4), 359-373 (2015).

12 Bouchelouche K, Choyke PL. Prostatespecific membrane antigen positron emission tomography in prostate cancer: a step toward personalized medicine. Curr. Opin. Oncol. 28(3), 216-221 (2016).

13 Panebianco V, Barchetti F, Musio D et al. Advanced imaging for the early diagnosis of local recurrence prostate cancer after radical prostatectomy. BioMed. Res. Int. 2014827265 (2014).

14 Thompson IM, Valicenti RK, Albertsen P et al. Adjuvant and salvage radiotherapy after prostatectomy: AUA/ASTRO guideline. J. Urol. 190(2), 441-449 (2013).

15 Fox JJ, Schoder H, Larson SM. Molecular imaging of prostate cancer. Curr. Opin. Urol. 22(4), 320-327 (2012).

16 Conti M. New prospects for PET in prostate cancer imaging: a physicist's viewpoint. EJNMMI Phys. 1(1), 11 (2014). 
17 Arimoto MK, Higashi T, Nishii R et al. 11C-methylaminoisobutyric acid (MeAIB) PET for evaluation of prostate cancer: compared with 18F-fluorodeoxyglucose PET. Ann. Nucl. Med. doi:10.1007/s12149-0161098-3 (2016) (Epub ahead of print).

18 Pyka T, Okamoto S, Dahlbender $M$ et al. Comparison of bone scintigraphy and 68Ga-PSMA PET for skeletal staging in prostate cancer. Eur. J. Nucl. Med. Mol. Imaging doi:10.1007/s00259-016-3435-0 (2016) (Epub ahead of print).

19 Liu J, Chen Z, Wang T et al. Influence of four radiotracers in PET/CT on diagnostic accuracy for prostate cancer: a bivariate random-effects meta-analysis. Cell Physiol. Biochem. 39(2), 467-480 (2016).

20 Evangelista L, Briganti A, Fanti S et al. New clinical indications for $\mathrm{F} / \mathrm{C}$-choline; new tracers for positron emission tomography and a promising hybrid device for prostate cancer staging: a systematic review of the literature. Eur. Urol. 70 (1), 161-175 (2016).

- Important systematic review for choline tracers.

21 Lindenberg L, Choyke P, Dahut W. Prostate cancer imaging with novel PET tracers. Curr. Urol. Rep. 17(3), 18 (2016).

22 Krause BJ, Souvatzoglou M, Treiber U. Imaging of prostate cancer with PET/CT and radioactively labeled choline derivates. Urol. Oncol. 31(4), 427-435 (2013).

23 Bauman G, Belhocine T, Kovacs M, Ward A, Beheshti M, Rachinsky I. 18F-fluorocholine for prostate cancer imaging: a systematic review of the literature. Prostate Cancer Prostatic Dis. 15(1), 45-55 (2012).

24 Fanti S, Minozzi S, Castellucci P et al. PET/ $\mathrm{CT}$ with ${ }^{11} \mathrm{C}$-choline for evaluation of prostate cancer patients with biochemical recurrence: meta-analysis and critical review of available data. Eur. J. Nucl. Med. Mol. Imaging 43(1), 55-69 (2016).

25 Mitchell CR, Lowe VJ, Rangel LJ, Hung JC, Kwon ED, Karnes RJ. Operational characteristics of ${ }^{11} \mathrm{C}$-choline positron emission tomography/computerized tomography for prostate cancer with biochemical recurrence after initial treatment. J. Urol. 189(4), 1308-1313 (2013).

26 Garcia JR, Cozar M, Soler M, Bassa P, Riera E, Ferrer J. Salvage radiotherapy in prostate cancer patients. Planning; treatment response and prognosis using C-choline PET/CT. Rev. Esp. Med. Nucl. Imagen. Mol. 35(4), 238-245 (2016).

27 Incerti E, Fodor A, Mapelli P et al. Radiation treatment of lymph node recurrence from prostate cancer: is 11C-choline PET/CT predictive of survival outcomes? J. Nucl. Med. 56(12), 1836-1842 (2015).

28

Giovacchini G, Incerti E, Mapelli P et al. $\left[{ }^{11} \mathrm{C}\right]$ Choline PET/CT predicts survival in hormone-naive prostate cancer patients with biochemical failure after radical prostatectomy. Eur. J. Nucl. Med. Mol. Imaging 42(6), 877-884 (2015).

29 Giovacchini G, Picchio M, Garcia-Parra R et al. 11C-choline PET/CT predicts prostate cancer-specific survival in patients with biochemical failure during androgendeprivation therapy. J. Nucl. Med. 55(2), 233-241 (2014).

30 Von Eyben FE, Kairemo K. Meta-analysis of ${ }^{11} \mathrm{C}$-choline and ${ }^{18} \mathrm{~F}$-choline PET/CT for management of patients with prostate cancer. Nucl. Med. Commun. 35(3), 221-230 (2014).

31 Colombie M, Campion L, Bailly C et al. Prognostic value of metabolic parameters and clinical impact of ${ }^{18} \mathrm{~F}$-fluorocholine PET/CT in biochemical recurrent prostate cancer. Eur. J. Nucl. Med. Mol. Imaging 42(12), 1784-1793 (2015).

32 Evangelista L, Cimitan M, Hodolic M, Baseric T, Fettich J, Borsatti E. The ability of $18 \mathrm{~F}$-choline PET/CT to identify local recurrence of prostate cancer. Abdom. Imaging 40(8), 3230-3237 (2015).

33 Zaorsky NG, Yamoah K, Thakur ML et al. A paradigm shift from anatomic to functional and molecular imaging in the detection of recurrent prostate cancer. Future Oncol. 10(3), 457-474 (2014).

34 Schiavina R, Brunocilla E, Borghesi M et al. Diagnostic imaging work-up for disease relapse after radical treatment for prostate cancer: how to differentiate local from systemic disease? The urologist point of view. Rev. Esp. Med. Nucl. Imagen. Mol. 32(5), 310-313 (2013).

35 Fuccio C, Castellucci P, Schiavina R et al. Role of 11C-choline PET/CT in the re-staging of prostate cancer patients with biochemical relapse and negative results at bone scintigraphy. Eur. J. Radiol. 81(8), e893-e896 (2012).

36 Vavere AL, Kridel SJ, Wheeler FB, Lewis JS. 1-11C-acetate as a PET radiopharmaceutical for imaging fatty acid synthase expression in prostate cancer. J. Nucl. Med. 49(2), 327-334 (2008).

37 Apolo AB, Lindenberg L, Shih JH et al. Prospective study evaluating Na18F-positron emission tomography/computed tomography (NaF-PET/CT) in predicting clinical outcomes and survival in advanced prostate cancer. J. Nucl. Med. 57(6), 886-892 (2016).
- A prospective study on utility of NaF PET in metastatic prostate cancer.

38 Afshar-Oromieh A, Malcher A, Eder $\mathrm{M}$ et al. PET imaging with a [68Ga] gallium-labelled PSMA ligand for the diagnosis of prostate cancer: biodistribution in humans and first evaluation of tumour lesions. Eur. J. Nucl. Med. Mol. Imaging 40(4), 486-495 (2013).

39 Mohsen B, Giorgio T, Rasoul ZS et al. Application of C-11-acetate positron-emission tomography (PET) imaging in prostate cancer: systematic review and meta-analysis of the literature. BJU Int. 112(8), 1062-1072 (2013).

40 Leisser A, Pruscha K, Ubl P et al. Evaluation of fatty acid synthase in prostate cancer recurrence: SUV of $\left[{ }^{11} \mathrm{C}\right]$ acetate PET as a prognostic marker. Prostate 75(15), 1760-1767 (2015).

41 Dusing RW, Peng W, Lai SM et al. Prostatespecific antigen and prostate-specific antigen velocity as threshold indicators in $11 \mathrm{C}$-acetate PET/CTAC scanning for prostate cancer recurrence. Clin. Nucl. Med. 39(9), 777-783 (2014).

42 Buchegger F, Garibotto V, Zilli T et al. First imaging results of an intraindividual comparison of ${ }^{11} \mathrm{C}$-acetate and ${ }^{18} \mathrm{~F}$-fluorocholine PET/CT in patients with prostate cancer at early biochemical first or second relapse after prostatectomy or radiotherapy. Eur. J. Nucl. Med. Mol. Imaging 41(1), 68-78 (2014).

43 Spick C, Polanec SH, Mitterhauser M et al. Detection of bone metastases using 11C-acetate PET in patients with prostate cancer with biochemical recurrence. Anticancer Res. 35(12), 6787-6791 (2015).

44 Turkbey B, Mena E, Shih J et al. Localized prostate cancer detection with $18 \mathrm{~F} \mathrm{FACBC}$ PET/CT: comparison with MR imaging and histopathologic analysis. Radiology 270 (3), 849-856 (2014).

45 Oka S, Hattori R, Kurosaki F et al. A preliminary study of anti-1-amino-3-18Ffluorocyclobutyl-1-carboxylic acid for the detection of prostate cancer. J. Nucl. Med. 48(1), 46-55 (2007).

46 Schuster DM, Votaw JR, Nieh PT et al. Initial experience with the radiotracer anti-1-amino-3-18F-fluorocyclobutane-1carboxylic acid with PET/CT in prostate carcinoma. J. Nucl. Med. 48(1), 56-63 (2007).

47 Schuster DM, Savir-Baruch B, Nieh PT et al. Detection of recurrent prostate carcinoma with anti-1-amino-3-18F-fluorocyclobutane1-carboxylic acid PET/CT and 111In- 
capromab pendetide SPECT/CT. Radiology 259(3), 852-861 (2011).

- A comparative study for FACBC PET versus ${ }^{111}$ In-capromab pendetide SPECT.

48 Nanni C, Schiavina R, Boschi S et al. Comparison of 18F-FACBC and 11C-choline $\mathrm{PET} / \mathrm{CT}$ in patients with radically treated prostate cancer and biochemical relapse: preliminary results. Eur. J. Nucl. Med. Mol. Imaging 40 (Suppl. 1), S11-S17 (2013).

49 Odewole OA, Tade FI, Nieh PT et al. Recurrent prostate cancer detection with anti-3-[F]FACBC PET/CT: comparison with CT. Eur. J. Nucl. Med. Mol. Imaging doi:10.1007/s00259-016-3383-8 (2016) (Epub ahead of print).

50 Koo PJ, Kwak JJ, Pokharel S, Choyke PL. Novel imaging of prostate cancer with MRI, MRI/US, and PET. Curr. Oncol. Rep. 17(12), 56 (2015).

51 Larson SM, Morris M, Gunther I et al. Tumor localization of 16beta-18F-fluoro-5alphadihydrotestosterone versus $18 \mathrm{~F}-\mathrm{FDG}$ in patients with progressive; metastatic prostate cancer. J. Nucl. Med. 45(3), 366-373 (2004).

52 Dehdashti F, Picus J, Michalski JM et al. Positron tomographic assessment of androgen receptors in prostatic carcinoma. Eur. J. Nucl. Med. Mol. Imaging 32 (3), 344-350 (2005).

53 Beattie BJ, Smith-Jones PM, Jhanwar YS et al. Pharmacokinetic assessment of the uptake of 16beta-18F-fluoro-5alpha-dihydrotestosterone (FDHT) in prostate tumors as measured by PET. J. Nucl. Med. 51(2), 183-192 (2010).

54 Vargas HA, Wassberg C, Fox JJ et al. Bone metastases in castration-resistant prostate cancer: associations between morphologic CT patterns, glycolytic activity, and androgen receptor expression on PET and overall survival. Radiology 271(1), 220-229 (2014).

55 Castellucci P, Jadvar H. PET/CT in prostate cancer: non-choline radiopharmaceuticals. $Q$. J. Nucl. Med. Mol. Imaging 367-374 (2012).

56 Hughes CT, Nix JW. Role of sodium fluoride PET imaging for identification of bony metastases in prostate cancer patients. Curr. Oncol. Rep. 16(5), 31 (2015).

57 Wibmer AG, Burger IA, Sala E, Hricak H, Weber WA, Vargas HA. Molecular imaging of prostate cancer. Radiographics 36(1), 142-159 (2016).

58 Jadvar H, Desai B, Ji L et al. Prospective evaluation of $18 \mathrm{~F}-\mathrm{NaF}$ and $18 \mathrm{~F}-\mathrm{FDG}$ PET/ $\mathrm{CT}$ in detection of occult metastatic disease in biochemical recurrence of prostate cancer. Clin. Nucl. Med. 37(7), 637-643 (2012).

59 Wondergem M, Van Der Zant FM, Van Der Ploeg T, Knol RJ. A literature review of
18F-fluoride PET/CT and 18F-choline or 11C-choline PET/CT for detection of bone metastases in patients with prostate cancer. Nucl. Med. Commun. 34(10), 935-945 (2013).

60 Azad GK, Cook GJ. Multi-technique imaging of bone metastases: spotlight on PET-CT. Clin. Radiol. 71(7), 620-631 (2016).

61 Bouchelouche K, Choyke PL, Capala J. Prostate specific membrane antigen - a target for imaging and therapy with radionuclides. Discov. Med. 9(44), 55-61 (2010).

62 Eiber M, Maurer T, Souvatzoglou M et al. Evaluation of hybrid ${ }^{68} \mathrm{Ga}$-PSMA ligand PET/ CT in 248 patients with biochemical recurrence after radical prostatectomy. J. Nucl. Med. 56(5), 668-674 (2015).

63 Maurer T, Eiber M, Schwaiger M, Gschwend JE. Current use of PSMA-PET in prostate cancer management. Nat. Rev. Urol. 13(4), 226-235 (2016).

64 Afshar-Oromieh A, Haberkorn U, Eder M, Eisenhut M, Zechmann CM. $\left[{ }^{68} \mathrm{Ga}\right]$ Gallium-labelled PSMA ligand as superior PET tracer for the diagnosis of prostate cancer: comparison with ${ }^{18} \mathrm{~F}-\mathrm{FECH}$. Eur. J. Nucl. Med. Mol. Imaging 39(6), 1085-1086 (2012).

65 Afshar-Oromieh A, Haberkorn U, Hadaschik $\mathrm{B}$ et al. PET/MRI with a ${ }^{68} \mathrm{Ga}$-PSMA ligand for the detection of prostate cancer. Eur. J. Nucl. Med. Mol. Imaging 40 (10), 1629-1630 (2013).

66 Weineisen M, Simecek J, Schottelius M, Schwaiger M, Wester HJ. Synthesis and preclinical evaluation of DOTAGAconjugated PSMA ligands for functional imaging and endoradiotherapy of prostate cancer. EJNMMI Res. 4(1), 63 (2014).

67 Roesch F, Riss PJ. The renaissance of the ${ }^{68} \mathrm{Ge} /{ }^{68} \mathrm{Ga}$ radionuclide generator initiates new developments in ${ }^{68} \mathrm{Ga}$ radiopharmaceutical chemistry. Curr. Top. Med. Chem. 10(16), 1633-1668 (2010).

68 Schottelius M, Wirtz M, Eiber M, Maurer T, Wester HJ. [ ${ }^{111}$ In] PSMA-I\&T: expanding the spectrum of PSMA-I\&T applications towards SPECT and radioguided surgery. EJNMMI Res. 5(1), 68 (2015).

69 Perera M, Papa N, Christidis D et al. Sensitivity, specificity, and predictors of positive ${ }^{68} \mathrm{Ga}$-prostate-specific membrane antigen positron emission tomography in advanced prostate cancer: a systematic review and meta-analysis. Eur. Urol. doi:10.1016/j. eururo.2016.06.021 (2016) (Epub ahead of print).

- A recent systematic review on prostatespecific membrane antigen-targeting PET tracers.
70 Afshar-Oromieh A, Avtzi E, Giesel FL et al. The diagnostic value of PET/CT imaging with the ${ }^{68} \mathrm{Ga}$-labelled PSMA ligand HBED-CC in the diagnosis of recurrent prostate cancer. Eur. J. Nucl. Med. Mol. Imaging 42(2), 197-209 (2015).

-. A largescale study on ${ }^{68} \mathrm{Ga}$-prostate-specific membrane antigen PET imaging.

71 Van Leeuwen PJ, Stricker P, Hruby G et al. Ga-prostate-specific membrane antigen has a high detection rate of prostate cancer recurrence outside the prostatic fossa in patients being considered for salvage radiation treatment. BJU Int. 117(5), 732-739 (2015).

72 Bluemel C, Krebs M, Polat B et al. ${ }^{68} \mathrm{Ga}-$ PSMA-PET/CT in patients with biochemical prostate cancer recurrence and negative ${ }^{18} \mathrm{~F}$-choline-PET/CT. Clin. Nucl. Med. 41(7), 515-521 (2016).

73 Morigi JJ, Stricker PD, Van Leeuwen PJ et al. Prospective comparison of

${ }^{18} \mathrm{~F}$-fluoromethylcholine versus ${ }^{68} \mathrm{Ga}$-PSMA PET/CT in prostate cancer patients who have rising PSA after curative treatment and are being considered for targeted therapy. J. Nucl. Med. 56(8), 1185-1190 (2015).

74 Afshar-Oromieh A, Zechmann CM, Malcher A et al. Comparison of PET imaging with a (68)Ga-labelled PSMA ligand and ${ }^{18} \mathrm{~F}$-choline-based PET/CT for the diagnosis of recurrent prostate cancer. Eur. J. Nucl. Med. Mol. Imaging 41(1), 11-20 (2014).

75 Afshar-Oromieh A, Haberkorn U, Schlemmer $\mathrm{HP}$ et al. Comparison of PET/CT and PET/ MRI hybrid systems using a ${ }^{68} \mathrm{Ga}$-labelled PSMA ligand for the diagnosis of recurrent prostate cancer: initial experience. Eur. J. Nucl. Med. Mol. Imaging 41(5), 887-897 (2014).

76 Freitag MT, Radtke JP, Hadaschik BA et al. Comparison of hybrid ${ }^{68} \mathrm{Ga}-\mathrm{PSMA}$ PET/MRI and ${ }^{68} \mathrm{Ga}$-PSMA PET/CT in the evaluation of lymph node and bone metastases of prostate cancer. Eur. J. Nucl. Med. Mol. Imaging 43(1), 70-83 (2016).

77 Rowe SP, Macura KJ, Ciarallo A et al. Comparison of prostate-specific membrane antigen-based ${ }^{18} \mathrm{~F}-\mathrm{DCFBC}$ PET/CT to conventional imaging modalities for detection of hormone-naive and castration-resistant metastatic prostate cancer. J. Nucl. Med. 57(1), 46-53 (2016).

78 Lütje S, Heskamp S, Cornelissen AS et al. PSMA ligands for radionuclide imaging and therapy of prostate cancer: clinical status. Theranostics. 5(12), 1388-1401 (2015).

79 Szabo Z, Mena E, Rowe SP et al. Initial evaluation of $\left[{ }^{18} \mathrm{~F}\right] \mathrm{DCFPyL}$ for prostate- 
specific membrane antigen (PSMA)-targeted pet imaging of prostate cancer. Mol. Imaging Biol. 17(4), 565-574 (2015).

Dietlein M, Kobe C, Kuhnert G et al. Comparison of $\left[{ }^{18} \mathrm{~F}\right] \mathrm{DCFPyL}$ and $\left[{ }^{68} \mathrm{Ga}\right]$ Ga-PSMA-HBED-CC for PSMA-PET imaging in patients with relapsed prostate cancer. Mol. Imaging Biol. 17(4), 575-584 (2015).

81 Sah BR, Burger IA, Schibli R et al. Dosimetry and first clinical evaluation of the new ${ }^{18} \mathrm{~F}$-radiolabeled bombesin analogue BAY
864367 in patients with prostate cancer. J. Nucl. Med. 56(3), 372-378 (2015).

82 Kahkonen E, Jambor I, Kemppainen J et al. In vivo imaging of prostate cancer using $\left[{ }^{68} \mathrm{Ga}\right]$-labeled bombesin analog BAY86-7548. Clin. Cancer Res. 19(19), 5434-5443 (2013). 